деятельностью, информационная система управления проектами не несёт в себе никакого положительного эффекта, а только затраты на её внедрение.

Также немаловажным риском является непонимание директором фирмы или её менеджером для чего необходима КСУП, вследствие чего, происходит неправильное формирование задач внедрения, и оценки ожидаемого эффекта. В результате появляются неадекватные ожидания участников внедрения и снижение их мотивации на успешный ввод в эксплуатацию КСУП, что приводит к снижению эффективности её работы или же отказу от неё вовсе.

Самой главной проблемой является неготовность самого предприятия, в целом, к внедрению данной системы и складывается это из множества факторов. Например, сама структура предприятия, которая не подготовлена к такому процессу или же не компетенция персонала компании. Также можно рассматривать проблему не компетенции руководства компании или недостаток мотивации сотрудников.

Все эти проблемы ведут к неправильному внедрению КСУП в производство и эффекты, которые планирует получать компания от её использования, стремятся к нулю. Чаще всего они ведут к крупным финансовым потерям компании, а так же качества проектов и кадровых потерь.

Несмотря на высокие риски внедрения, при правильном подходе и анализе проблемы, эффективность внедрения КСУП говорит сама за себя, а именно, что 94\% опрошенных отмечали - увеличение стоимости их организации, 50\% - улучшения исполнения проектов, 36\% - увеличения удовлетворения заказчиков, $54 \%$ - улучшение финансового исполнения, $30 \%$ - общее повышение удовлетворения штатных работников[4].

$$
* * *
$$

1. Разработка функциональной модели информационной системы автоматизации управления деятельностью компании / Медникова О.В., Смирнов С.А., Строев П.С., // eLibrary - научная электронная библиотека [Электронный ресурc] https://elibrary.ru/item.asp?id=29244398

2. Богданов, В. В. Управление проектами. Корпоративная система - шаг за шагом. - М.: Манн, Иванов и Фербер, 2012. - 248 c.

3. Попова М.И. Необходимо ли внедрять КСУП на предприятии. - Электронный научно-практический журнал «Современные научные исследования и инновации» [Электронный ресурс] http://web.snauka.ru/issues/2016/03/65337

4. Корпоративная система управления проектами (КСУП) [Электронный ресурс] http://mahamba.com/ru/korporativnaya-sistema-upravleniya-proektami-ksup

\title{
Панченко А.O.
}

\section{Анализ и исследование существующих протоколов Интернета вещей}

\section{Дальневосточный федеральный университет} (Россия, Владивосток)

doi:10.18411/lj-31-03-2018-16

idsp: 000001:lj-31-03-2018-16

\section{Аннотация}

В статье приведен краткий обзор протоколов прикладного уровня, наиболее подходящих и часто используемых в концепции интернета вещей (IoT). Рассмотрены их основные достоинства и недостатки, проведен сравнительный анализ по наиболее информативным критериям оценки эффективности сети.

Ключевые слова: Интернет вещей, ІоТ, протокол, М2М.

В последнее время концепция «Интернет вещей» совершила значительный скачок в развитии, так как в современном мире происходит стремление к созданию полностью автоматизированных систем связи, сбора, обработки и анализа информационных данных. 
При разработке систем связи, способных решать задачи IоТ необходимо учитывать специфику данной концепции. Важным, информативным показателем при анализе протоколов прикладного уровня можно считать контроль качества сервиса QoS (Quality of Service), который позволяет характеризовать гибкость доставки данных [1]. Также, можно отнести адресацию устройств в сети - способность поиска устройств в огромной базе IоT. Следующим, немаловажным показателем системы является ее энергетическая эффективность, повышение которой приводит к увеличению автономности сети. Так как все протоколы разрабатываются для решения определенного круга задач, то каждый из них имеет свои ключевые особенности, свои способы взаимодействия устройств, которые также необходимо взять во внимание.

Для решения задач, остро поставленных на данный момент в концепции ІоТ, было как разработано, так и адаптировано немало протоколов, каждый из которых заметно отличается друг от друга: MQTT (Message Queue Telemetry Transport), CoAP (Constrained Application Protocol), AMQP (Advanced Message Queuing Protocol), XMPP (Extensible Messaging and Presence Protocol), DDS (Data Distribution Service) и т.д [3].

Имея сложный показатель QoS, можно создать гибкую, масштабируемую систему. Tак MQTT и DDS за счет наличия нескольких уровней качества сервиса способны обеспечить гибкую и масштабируемую систему. Большинство протоколов работают поверх TCP (Transmission Control Protocol), что позволяет простейшим способом обеспечить надежность доставки данных [2]. UDP (User Datagram Protocol) используется лишь в CoAP и DDS. Это значительно снижает объем служебной информации сообщений, а надежность передачи данных достигается уже за счет программных решений. Так, например, в СоАР используется три типа сообщений, которые позволяют создать гибкую надежную систему с возможностью синхронизации устройств [4]. При необходимости, возможно создать систему с надежной доставкой данных получателю. Также DDS способен обеспечить синхронизацию, надежность и контроль присутствия устройств.

Сравнивая возможность поиска устройств в сети, стоит отметить ХМРР за счет его удобной системы адресации, которая позволяет быстро выполнять обработку больших массивов данных. MQTT в данном случае имеет преимущество за счет типа связи устройств с сервером. Если есть возможность подключиться к брокеру, можно получить доступ сразу ко всем его устройствам. AMQP за счет передачи данных очередями объединяет устройства через потоки сообщений. DDS не имеет преимуществ в механизме адресации устройств [3].

В вопросе энергетической эффективности стоит учитывать избыточность передаваемой информации. Использование протокола ТСР на транспортном уровне влечет дополнительные накладные расходы на установление соединения и подтверждение доставки данных. Так CoAP, будучи бинарным и используя UDP, является одним из самых энергоэффективных протоколов из вышеперечисленных. Протокол MQTT является бинарным и способен обеспечить хорошие энергетические показатели системы за счет своей структуры, несмотря на использование ТСР. Взаимодействие в данном случае происходит по шаблону “издатель-подписчик", это повышает эффективность системы, так как устройства работают только по необходимости, а все остальное время находятся в режиме ожидания с минимальным потреблением энергии [2]. Протоколы МQТТ и СоАР не требуют постоянного соединения для работы устройств и хорошо адаптированы для маломощных устройств Интернета вещей [4]. AMQP и XMPP используют ТСР и не адаптированы для достижения высокой энергетической эффективности. DDS соединяет устройства друг с другом децентрализовано с малой задержкой. Подразумевается, что устройства будут иметь высокую производительность с большим потреблением энергии, поэтому о хороших энергетических показателях речь в данном случае не идет. 
В заключение надо отметить, что основные особенности каждого протокола заложены в область их применения. Так передача данных между различными узлами сети значительно отличается друг от друга. Но все же, основная задача ІоТ - обеспечение коммуникации между мобильными, автономными устройствами, поэтому одним из важнейших показателей системы является энергетическая эффективность. Которая достигается с использованием протоколов СоАР и MQTT, наиболее адаптированных под взаимодействие маломощных узлов.

\section{$* * *$}

1. Росляков А.В. Интернет вещей: учебное пособие [текст] / А.В. Росляков, С.В. Ваняшин, А.Ю. Гребешков. - Самара: ПГУТИ, 2015. - 200 с.

2. Фам В. Д., Юльчиева Л. О., Киричек Р. В. Исследование протоколов взаимодействия интернета вещей на базе лабораторного стенда // Информационные технологии и телекоммуникации. 2016. Том 4. № 1. C. 55-67.

3. Гойхман В., Савельева А. Аналитический обзор протоколов Интернета вещей. // Технологии и средства связи. - 2016. № 4. С. 32-37.

4. Гойхман В., Абраменкова Д. Протокол Интернета вещей СоАР [Текст] // Технологии и средства связи. - 2017. - № 4. - С. 20-24.

\section{Тимофеева Н.В., Тропников А.С. \\ Оптимизация деятельности по поддержке работы пользователей в сети предприятия}

Севернылй (Арктический) федеральный университет имени М.В. Ломоносова, Институт судостроения и морской арктической техники (Россия, Северодвинск)

doi:10.18411/lj-31-03-2018-17

idsp: 000001:lj-31-03-2018-17

\section{Аннотация}

Статья посвящена вопросу оптимизации деятельности работ IT-специалистов, занимающихся обслуживанием пользователей, с помощью внедрения ITSM-систем. В работе рассмотрено прототип проектного решения организационных проблем, возникающих в ходе работ.

Ключевые слова: оптимизация, пользователь, ITSM-система, IT-поддержка, Service Desk, Help Desk.

Поддержание работоспособности компьютеров на рабочих местах, оперативное решение возникающих проблем у пользователей и мониторинг оборудования на предприятии - это основные требования, что предъявляет работодатель к сотрудникам технической поддержки.

«Поддержка пользователей» - одна из самых типовых задач, выполняемых различными техническими специалистами. В малых компаниях, не насчитывающих и трех десятков автоматизированных рабочих мест (AРM), данной работой может заниматься штатный инженер, устраняющий неполадки в меру своих сил.

Более крупные компании могут нанимать аутсорсинговые фирмы, предоставляющие услуги поддержки пользователям и специализирующиеся на оказании квалифицированных IT-услуг.

Предприятия же, насчитывающие уже сотни или даже тысячи АРM, могут создавать свои собственные подразделения, входящие в структуру компании - Службы технической поддержки. Данные подразделения не только занимаются непосредственной поддержкой пользователей, но также создают для выполнения своей основной задачи различные Автоматизированные Информационные Системы, позволяющие обрабатывать огромный поток заявок от сотрудников компании. 